\title{
Enhanced Responsiveness to Novelty and Cocaine Is Associated with Decreased Basal Dopamine Uptake and Release in the Nucleus Accumbens: Quantitative Microdialysis in Rats under Transient Conditions
}

\author{
Vladimir I. Chefer, Irina Zakharova, and Toni S. Shippenberg \\ Integrative Neuroscience Section, Behavioral Neuroscience Branch, National Institutes of Health/National Institute on Drug Abuse/Intramural Research \\ Program, Baltimore, Maryland 21224
}

\begin{abstract}
Male rats were screened for their response to a novel environment and designated as high responders (HRs) or low responders (LRs). They then received daily injections of saline or cocaine $\left(20 \mathrm{mg} / \mathrm{kg}\right.$, i.p.). Basal and cocaine-evoked extracellular dopamine $\left(\mathrm{DA}_{\text {ext }}\right)$ levels as well as basal DA uptake rate and cocaine-evoked inhibition of uptake in the nucleus accumbens were determined on abstinence day 3 using quantitative microdialysis under transient conditions. The kinetics of uptake, dopamine transporter (DAT) expression, and $\left[{ }^{3} \mathrm{H}\right](-)-2-\beta$-carbomethoxy-3- $\beta$-(4-fluorophenyl)tropane 1,5-naphthalenedisulfonate $\left(\left[{ }^{3} \mathrm{H}\right] \mathrm{WIN} 35428\right)$ binding were also examined. The locomotor activating effects of cocaine and the magnitude of behavioral sensitization were greater in HRs. Saline-treated HRs had lower basal uptake than LRs. DA uptake after cocaine challenge was also lower in these animals. Although basal $\mathrm{DA}_{\text {ext }}$ did not differ,

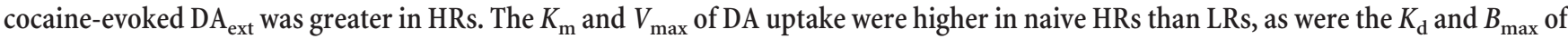
$\left[{ }^{3} \mathrm{H}\right]$ WIN35428 binding. DAT protein expression did not differ. Previous cocaine exposure decreased basal DA uptake. It increased cocaine-evoked $\mathrm{DA}_{\text {ext }}$ and decreased the cocaine-induced inhibition of uptake, especially in HRs, indicating greater DA release during cocaine challenge in this phenotype. We hypothesize that lower basal uptake in HRs results from a decrease in DAT binding affinity that is compensated for, in part, by an increased number of plasma membrane binding sites. Basal uptake, but not $\mathrm{DA}_{\mathrm{ext}}$, was lower in HRs, indicating lower basal $\mathrm{DA}$ release in $\mathrm{HRs}$. The finding that cocaine-evoked $\mathrm{DA}_{\text {ext }}$ is higher in naive and cocaine-exposed HRs suggests that the greater responsiveness of DA neurons in HRs may underlie the enhanced behavioral responses that characterize this phenotype.
\end{abstract}

Key words: individual differences in response to novelty; dopamine; dopamine uptake and release; nucleus accumbens; cocaine; transient no net flux microdialysis

\section{Introduction}

One focus of addiction research is identification of the neural substrates underlying individual differences in vulnerability to develop compulsive drug-seeking behavior. The locomotor response to a novel environment is predictive of individual differences in the behavioral effects of psychostimulants (Piazza and Le Moal, 1996). High responders (HRs) exhibit greater locomotor activity in an open field, exhibit greater psychostimulant-induced activity, and have a greater propensity to acquire psychostimulant self-administration than individuals exhibiting less activity in an open field [low responders (LRs)] (Piazza et al., 1989).

The role of the mesocorticolimbic system in psychostimulantinduced behaviors has prompted hypotheses that differences in the activity of DA neurons projecting to the nucleus accumbens (NAc) may underlie these phenotypes. Indeed, NAc microinjections of a DA antagonist (Hooks and Kalivas, 1995) prevent

Received Nov. 20, 2002; revised Jan. 17, 2003; accepted Jan. 22, 2003.

This research was supported by the Intramural Research Program, National Institute on Drug Abuse, National Institutes of Health.

Correspondence should be addressed to Dr. T. S. Shippenberg, Integrative Neuroscience Section, Behavioral Neuroscience Branch, National Institute on Drug Abuse/Intramural Research Program, 5500 Nathan Shock Drive, Baltimore, MD 21224. E-mail: tshippen@intra.nida.nih.gov.

Copyright $\odot 2003$ Society for Neuroscience $\quad 0270-6474 / 03 / 233076-09 \$ 15.00 / 0$ novelty-induced locomotor activity, and HRs have a higher DOPAC/DA ratio in the NAc (Piazza et al., 1991). Microdialysis studies showed that, although basal DA levels do not differ, psychostimulant-induced increases in NAc DA are greater in HRs (Hooks et al., 1991b; Rouge-Pont et al., 1993). However, conclusions derived from postmortem studies are limited because extracellular concentrations cannot be determined. Furthermore, although no difference between HRs and LRs in basal dialysate DA levels was reported previously (Hooks et al., 1991b), dialysate levels not only do not permit quantification of extracellular levels, but changes in this parameter can result from changes in uptake and/or extracellular levels. Moreover, changes in DA uptake can alter the microdialysis probe extraction fraction $\left(\mathrm{E}_{\mathrm{d}}\right)$, leading to overestimations or underestimations of extracellular levels (Justice, 1993; Shippenberg and Thompson, 1997).

No-net-flux microdialysis provides an estimate of basal extracellular dopamine $\left(\mathrm{DA}_{\text {ext }}\right)$ levels that is independent of $\mathrm{E}_{\mathrm{d}}$ alterations. Using this technique, Hooks et al. (1992) reported that basal $\mathrm{DA}_{\mathrm{ext}}$, but not dialysate DA levels, were elevated in the NAc of HRs. $E_{d}$, an indirect measure of DA uptake, did not differ. This finding is surprising in view of reports (Shippenberg and Thompson, 1997; Shippenberg et al., 1999) that lack of concordance between the effects of a manipulation on dialysate and $\mathrm{DA}_{\mathrm{ext}}$ 
levels results from altered uptake. Moreover, a recent chronoamperometry study (Sabeti et al., 2002) provided evidence that differences in DA transporter (DAT) function may reflect different addiction phenotypes. It is notable also that in the study by Hooks et al. (1992), $\mathrm{E}_{\mathrm{d}}$ was determined before cocaine challenge, and this value was used to calculate $\mathrm{DA}_{\text {ext }}$ after cocaine challenge. Given the relationship between changes in DA uptake and $\mathrm{E}_{\mathrm{d}}$, and given that cocaine inhibits uptake, the failure to redetermine $E_{d}$ after cocaine administration may have confounded measurement of DA dynamics.

Quantitative microdialysis under transient conditions (Olson and Justice, 1993) permits assessment of alterations in $\mathrm{DA}_{\text {ext }}$ and DA uptake as a function of time after drug administration. A between-group design, in which separate groups of animals are perfused with a single DA concentration, enables quantification of $\mathrm{DA}_{\mathrm{ext}}$ and $\mathrm{E}_{\mathrm{d}}$ at various times. Using this technique, we have characterized basal and cocaine-evoked NAc DA dynamics in naive HRs and LRs and those with a history of cocaine administration. DAT function and the kinetics of DA uptake were assessed in vitro.

\section{Materials and Methods}

Animals. Male Sprague Dawley rats (Charles River Laboratories, Wilmington, MA) weighing 250-300 gm were housed in groups of three per cage for at least 1 week before use. They were maintained in a temperature- and humidity-controlled environment under a $12 \mathrm{hr}$ light/ dark cycle with laboratory rat chow and water available ad libitum. All experiments were performed during the light cycle. Animals used in these studies were maintained in facilities accredited by the American Association for the Accreditation of Laboratory Animal Care, and all experiments were conducted in accordance with the guidelines of the Institutional Care and Use Committee of the National Institute on Drug Abuse (Rockville, MD), National Institutes of Health.

Selection of HRs and LRs to novelty. All animals were tested for their locomotor response to a novel environment 1 week before the commencement of the pretreatment regimens. Locomotor activity was measured in Plexiglas cages $(43 \times 44 \times 25 \mathrm{~cm})$ using an Opto-Varimex system (Columbus Instruments, Columbus, $\mathrm{OH}$ ). The horizontal sensor of the system consisted of two arrays of 15 infrared beams, which were placed perpendicular to each other. The beams were spaced $2.4 \mathrm{~cm}$ apart. The Opto-Varimex was equipped with a Columbus Instruments data collection system and software package for an IBM computer (Auto-Track System V3.20A; Columbus Instruments). The location of an animal was read by the Auto-Track system 10 times each second. The distance traveled by each animal during a single $2 \mathrm{hr}$ session was determined. Animals were designated as HRs or LRs depending on whether their activity was above or below the median value (Piazza et al., 1989, 1990). Rats were tested in groups of 16 animals. Four animals with values closest to the median were not used in the subsequent experiments.

Surgical procedures. Animals were anesthetized with Equithesin $(3 \mathrm{ml} /$ $\mathrm{kg}$ ) and implanted unilaterally with a microdialysis guide cannula (CMA/11; CMA/Microdialysis, Acton, MA) aimed at the NAc using standard stereotaxic techniques. Each rat was mounted in a stereotaxic apparatus (David Kopf Instruments, Tujunga, CA) with the upper incisor bar set $3.5 \mathrm{~mm}$ below the interaural line. The coordinates (anterior, +1.7 relative to bregma; lateral, \pm 0.9 ; ventral, -6.0 from the dura surface) were based on the atlas of Paxinos and Watson (1986). The microdialysis guide cannula and a head-mount screw, which permitted attachment of the animal to a spring tether, were cemented in place with dental acrylic and three stainless-steel screws.

Drug treatments. Equal numbers of animals were assigned to the cocaine and saline pretreatment groups. After 3-4 d of handling and recovery, rats received daily injections of either saline $(1.0 \mathrm{ml} / \mathrm{kg}$, i.p.) or cocaine $(20 \mathrm{mg} / \mathrm{kg}$, i.p.) in their home cages for $5 \mathrm{~d}$. Cocaine hydrochloride was supplied by the Research Technology Branch of the National Institute on Drug Abuse and prepared in sterile saline.
Microdialysis procedures. Microdialysis experiments were conducted $3 \mathrm{~d}$ after the last cocaine or saline injection. A microdialysis probe (CMA/ 11; membrane dimension $0.24 \times 2 \mathrm{~mm}$ ) was manually inserted into the microdialysis guide cannula $\sim 12 \mathrm{hr}$ before the commencement of the experiments. The inlet tubing of the probe was connected to a microinfusion pump (Instech syringe pump, model 2000, Instech, Plymouth Meeting, PA) via a dual quartz-lined swivel (Instech), and the animal was placed into a Plexiglas test chamber $(40 \times 40 \times 35 \mathrm{~cm})$. The microdialysis probe was flushed overnight at a flow rate of $0.3 \mu \mathrm{l} / \mathrm{min}$ with artificial CSF (aCSF), containing (in mM): $145 \mathrm{NaCl}, 2.8 \mathrm{KCl}, 1.2 \mathrm{MgCl}_{2}, 1.2$ $\mathrm{CaCl}_{2}, 0.25$ ascorbic acid (to minimize oxidation of DA during no-netflux experiments) and 5.4 D-glucose, adjusted to $\mathrm{pH} 7.2$ using $\mathrm{NaOH}$ or $\mathrm{H}_{3} \mathrm{PO}_{4}$ (HPLC grade). The aCSF was filtered through a $0.22 \mu \mathrm{m}$ filter (Millipore Corp., Bedford, MA). Placing animals into the test chamber $12 \mathrm{hr}$ before the experiment and overnight perfusion of probes with aCSF (at a flow rate of $0.3 \mu \mathrm{l} / \mathrm{min}$ ) allowed animals to habituate to the microdialysis environment and the levels of DA to return to baseline after probe insertion. On the day of the experiment, perfusate was replaced with one of three different concentrations of DA in aCSF $\left(\mathrm{DA}_{\mathrm{in}}: 0,10\right.$, or $40 \mathrm{nM})$. Samples were collected in microcentrifuge tubes every $10 \mathrm{~min}$ at a flow rate of $0.6 \mu \mathrm{l} / \mathrm{min}$ after a $50-60 \mathrm{~min}$ equilibration period.

Five consecutive samples were collected for the determination of basal levels of $\mathrm{DA}_{\text {ext }}$ and $\mathrm{E}_{\mathrm{d}}$. Animals were then injected with cocaine (20 $\mathrm{mg} / \mathrm{kg}$, i.p.), and samples were collected for another $50 \mathrm{~min}$. Samples and DA standards were frozen on dry ice in $6 \mu \mathrm{l}$ aliquots and then placed at $-80^{\circ} \mathrm{C}$ until analyzed.

Evaluation of behavioral response to cocaine challenge. The behavioral effects produced by the acute challenge dose of cocaine were quantified using a modification of the behavioral rating scale of Ellinwood and Balster (1974) For each 5 min observational period, each animal was assigned a rating score from 1 to 9 . The definition of each score was as follows: 1 , asleep; 2 , inactive, lying down, eyes open; 3 , normal in-place activities (grooming, etc.); 4, moving about the cage, sniffing, rearing; 5, hyperactive, increased locomotor activity with rapid changes in position; 6, slow-patterned, repetitive explorations of the cage at normal level of activity; 7, fast-patterned, repetitive exploration with hyperactivity; 8 , restricted, in-place repetitive behavior; 9 , exaggerated in-place repetitive behavior, backing up, jumping.

Histology. After the completion of microdialysis experiments, all animals were deeply anesthetized with pentobarbital ( $>80 \mathrm{mg} / \mathrm{kg}$, i.p.) and killed by decapitation. The brains were removed and frozen. Histological verification of the site of probe placement was obtained via coronal sections (20 $\mu \mathrm{m}$ thick) using a microtome (model 5030; Hacker Instruments, Fairfield, NJ). Representative sections were analyzed according to the atlas of Paxinos and Watson (1986). Only data obtained from animals with histologically correct placements were used for subsequent statistical analysis.

Chromatographic analysis of brain microdialysates. The samples and DA standards were thawed and placed in a CMA/200 refrigerated microsampler (CMA/Microdialysis) connected to an HPLC system with electrochemical detection. The separation and quantification of DA was achieved by using a microbore HPLC column $(100 \times 2 \mathrm{~mm}$; C- $18 ; 3 \mu \mathrm{M}$; MF-8957; Bioanalytical Systems, West Lafayette, IN) and an LC-4C amperometric detector (Bioanalytical Systems). The applied potential was set at $650 \mathrm{mV}$ versus $\mathrm{Ag} / \mathrm{AgCl}$ reference electrode. The mobile phase consisted of $0.15 \mathrm{M} \mathrm{NaH}_{2} \mathrm{PO}_{4}, 1.7 \mathrm{~mm}$ sodium octyl sulfate, $1.0 \mathrm{~mm}$ EDTA, 12\% methanol, and an apparent $\mathrm{pH}$ of 5.0. All reagents were analytical grade and were obtained from Sigma (St. Louis, MO) and Fluka BioChemica (Ronkonkoma, NY). The mobile phase was filtered through a $0.22 \mu \mathrm{m}$ filter (Millipore Corp.) and degassed with helium for $20 \mathrm{~min}$. The samples were analyzed at a flow rate of $0.5 \mathrm{ml} / \mathrm{min}$ and a column pressure of $2800-3000$ psi. The elution time of DA was 3-3.5 $\mathrm{min}$. The range of the DA standards was $0-40 \mathrm{~nm}$. The injection volume was $5 \mu \mathrm{l}$, and the limit of detection for DA was $<0.5 \mathrm{~nm}$. Chromatographic data were collected and processed using a WinChrom Chromatography Data Management System.

Rotating disk electrode measurements of DA uptake. In separate experiments, rotating disk electrode ( $\mathrm{RDE}$ ) voltammetry was used to measure the initial velocity of DA clearance in minced NAc tissue from drug-naive 
HRs and low LRs. Animals were screened for their response to a novel environment and habituated to the laboratory environment for $4 \mathrm{~d}$ to reduce stress on the day of the experiment. Five days after locomotor activity testing, rats were killed by decapitation and brains were rapidly removed. The NAc was dissected as described previously (Thompson et al., 2000; Chefer and Shippenberg, 2002; Zapata and Shippenberg, 2002) to analyze the rate of DA uptake (Meiergerd and Schenk, 1995; Earles and Schenk, 1998). In brief, the NAc tissue was placed in a $1.5 \mathrm{ml}$ microcentrifuge tube and weighed. A total of $500 \mu$ l of ice-cold physiological buffer (in nM: $124 \mathrm{NaCl}, 3 \mathrm{KCl}, 1.24 \mathrm{KH}_{2} \mathrm{PO}_{4}, 1.3 \mathrm{MgSO}_{4}, 2.5 \mathrm{CaCl}_{2}, 26$ $\mathrm{NaHCO}_{3}, 10$ D-glucose, $\mathrm{pH} 7.4$, gassed with $95 \% \mathrm{O}_{2}-5 \% \mathrm{CO}_{2}$ mix) was added to the tissue. The tissue was washed three times by removing and then replacing $400 \mu \mathrm{l}$ of the buffer. Next, $400 \mu \mathrm{l}$ of the ice-cold buffer was replaced with room temperature buffer, and the tissue was allowed to incubate at room temperature for $4 \mathrm{~min}$. Then the tissue was removed from the tube, placed on a glass dish, and minced with two scalpel blades. The minced tissue was placed into a Teflon electrochemical cell (with auxiliary and reference electrodes) containing $300 \mu \mathrm{l}$ of $37^{\circ} \mathrm{C}$ physiological buffer. The RDE was then lowered into the suspension. The rotation rate of the electrode was set at $4000 \mathrm{rpm}$, and the suspension was maintained at $37^{\circ} \mathrm{C}$ and subjected to a constant stream of $95 \% \mathrm{O}_{2}-5 \% \mathrm{CO}_{2}$ gas directed over the top of the electrochemical cell.

Voltammetric measurements were made as described previously (Meiergerd and Schenk, 1995; Earles and Schenk, 1998). The applied potential was $+450 \mathrm{mV}$ versus $\mathrm{Ag} / \mathrm{AgCl}$ reference electrode. Data acquisition and analysis were performed using Microcal Origin (Microcal Software Inc., Northampton, MA).

The voltage output was monitored until a relatively stable baseline was obtained ( $\cong 15 \mathrm{~min}$ ), and then $6 \mu$ l of one of the known concentrations of DA was added to the suspension (final DA concentrations in solution were $1,2,3,4,6,8$, and $10 \mu \mathrm{M})$. The resultant signals were detected as changes in voltage output from an electrochemical detector (LC 4B; Bioanalytical Systems Inc.) versus time and recorded with a data acquisition system. The initial rate of DA decay after addition of DA, which has been shown to result solely from the DAT-mediated uptake of the DA into the tissue (Povlock and Schenk, 1997), was calculated for a $10 \mathrm{sec}$ interval. The initial decay of the DA signal in the absence of tissue was recorded at the end of each experimental day. The rates of this nonspecific decay were subtracted from the rates observed in the presence of tissue for calculation of the initial clearance rates at each DA concentration. Data were normalized for the tissue weight and expressed as the initial velocity of DA uptake in picomoles per second per gram of wet weight tissue. Values of $K_{\mathrm{m}}$ and $V_{\max }$ were estimated by fitting experimentally obtained values of the initial velocity for each DA concentration to the Michaelis-Menten equation using commercially available software (Graph Pad Prism 3.0; Graph Pad, San Diego, CA). The $V_{\max } / K_{\mathrm{m}}$ ratio, which provides an index of the efficiency of DA clearance (Sabeti et al., 2002), was determined for each group.

$\left[{ }^{3} \mathrm{H}\right](-)-2-\beta$-carbomethoxy-3- $\beta$-(4-fluorophenyl)tropane 1,5-naphthalenedisulfonate binding and DAT Western blots. $\left[{ }^{3} \mathrm{H}\right](-)-2-\beta$-carbomethoxy-3- $\beta$-(4-fluorophenyl)tropane 1,5 -naphthalenedisulfonate $\left(\left[{ }^{3} \mathrm{H}\right]\right.$ WIN35428) binding in synaptosomal preparations was determined as described by Kokoshka et al. (1998). NAc synaptosomes were resuspended in ice-cold $0.32 \mathrm{M}$ sucrose in Krebs'-Ringer's bicarbonate buffer, pH 7.4, for [ ${ }^{3} \mathrm{H}$ ]WIN35428 (86 Ci/mmol; PerkinElmer Life Sciences, Emeryville, CA) binding. [ $\left.{ }^{3} \mathrm{H}\right] \mathrm{WIN} 35428$ binding ( $2 \mathrm{~nm}$ final concentration) was conducted in $0.32 \mathrm{M}$ sucrose-Krebs'-Ringer's buffer, $\mathrm{pH}$ 7.4 , with $50 \mu \mathrm{g}$ of synaptosomal protein per reaction tube in the presence of different concentrations of unlabeled WIN35428 ranging from 0.1 to $5000 \mathrm{~nm}$. Samples were incubated on ice for $2 \mathrm{hr}$ and then filtered through Whatman GF/B filters (Brandel, Gaithersburg, MD) soaked previously in $0.4 \%$ polyethylenimine. Filters were washed rapidly three times with $5 \mathrm{ml}$ of ice-cold phosphate-buffered $0.32 \mathrm{M}$ sucrose, $\mathrm{pH} 7.4$, using a filtering manifold (Brandel). Radioactivity trapped in filters was counted using $5 \mathrm{ml}$ of Bio-Safe II scintillation fluid (Research Products International, Mt. Prospect, IL) added to each tube. $\mathrm{IC}_{50}$ values were determined using one-site competition nonlinear curve fitting (Graph Pad Prism 3.0). The Cheng and Prusoff equation was used to calculate the $K_{\mathrm{d}}$ from the $\mathrm{IC}_{50}$.
Immunoblots of DAT were obtained using antiserum B16 (Chemicon, Temecula, CA), generated against rabbit DAT amino acids 42-59 of N terminus. Synaptosomes from NAc were solubilized in SDS-sample loading buffer, and 20-30 $\mu \mathrm{g}$ of protein was electrophoresed on $10 \%$ SDSpolyacrylamide gels. After transfer to polyvinylidene difluoride membranes and blocking with $5 \%$ nonfat milk, the membranes were probed overnight at $4^{\circ} \mathrm{C}$ with DAT antibody diluted 1:2000, followed by $1 \mathrm{hr}$ of incubation with goat anti-rabbit HRP-conjugated secondary antibody (1:2000; Cell Signaling Technology, Inc., Beverly, MA). Immunoreactive bands were visualized by ECL on hypersensitive ECL film (Amersham Biosciences, Arlington Heights, IL). Values of DAT protein were normalized by the levels of actin immunoreactivity. The amount of immunoreactive material in each line was quantified using NIH Image 1.61 software.

Data analysis. Microdialysis data are expressed in nanomolar concentrations. The net change in $\mathrm{DA}\left(\mathrm{DA}_{\mathrm{in}}-\mathrm{DA}_{\text {out }}\right)$ was calculated for each animal and then averaged for each perfusion group $\left(\mathrm{DA}_{\mathrm{in}}: 0,10\right.$, and 40 $n \mathrm{n} D A)$. The average net change in DA was plotted against $\mathrm{DA}_{\text {in }}$ for each time point in each pretreatment group. $\mathrm{DA}_{\mathrm{ext}}$ and $\mathrm{E}_{\mathrm{d}}$ were assessed from the linear regression equation as described previously (Parsons et al., 1991a,b). The point at which no DA was gained or lost $\left(\mathrm{DA}_{\text {in }}-\mathrm{DA}_{\text {out }}=\right.$ 0 ) represents an estimate of $\mathrm{DA}_{\text {ext }}$ concentration. The slope of the linear regression represents the $\mathrm{E}_{\mathrm{d}}$, an indirect measure of DA uptake. The SEM for $E_{d}$ was assessed directly from regression statistics. The SEM for $\mathrm{DA}_{\mathrm{ex}}$ was calculated using the equation $\operatorname{SEM}_{\text {ext }}=\left[(\mathrm{Sb} / \mathrm{b})^{2}+(\mathrm{Sm} / \mathrm{m})^{2}\right]^{1 / 2}$ from Olson and Justice (1993), where SEM ${ }_{\text {ext }}$ is the SEM for the $\mathrm{DA}_{\text {ext }}$ concentration, $S b$ is the SD of the $y$-intercept, $b$ is the $y$-intercept, $S m$ is the $\mathrm{SD}$ of the $\mathrm{E}_{\mathrm{d}}$, and $m$ is the $\mathrm{E}_{\mathrm{d}}$.

The cocaine-evoked $\mathrm{DA}_{\text {ext }}$ concentration and $\mathrm{E}_{\mathrm{d}}$ expressed as a percentage of basal values as well as kinetic parameters for basal DA uptake and the results of $\left[{ }^{3} \mathrm{H}\right]$ WIN35428 binding were compared between LR and HR animals via unpaired $t$ test with Welch's correction. The behavioral rating score data were converted to area under the curve (AUC) values and subjected to a two-factor ANOVA (pretreatment: cocaine vs saline; response to novelty: LRs vs HRs). The levels of $\mathrm{DA}_{\mathrm{ext}}$ and the $\mathrm{E}_{\mathrm{d}}$ were subjected to a two-factor ANOVA (basal vs cocaine-challenge conditions; HRs vs LRs). The accepted value of significance for all tests was $p \leq 0.05$. The data are presented as mean \pm SEM.

\section{Results}

\section{Behavioral sensitization to cocaine in HR and LR animals}

Three days after the cessation of the treatment regimens, the acute administration of cocaine $(20 \mathrm{mg} / \mathrm{kg}$, i.p.) increased locomotor activity in all experimental groups (HRs and LRs, saline or cocaine pretreatment) (Fig. 1). ANOVA revealed significant main effects of pretreatment (cocaine vs saline: $F_{(1,49)}=47.56$; $p<0.01$ ) and individual differences (HRs vs LRs: $F_{(1,49)}=54.25$; $p<0.01)$ on cocaine-evoked locomotor activity. There was a significant pretreatment by individual differences interaction $\left(F_{(1,49)}=7.52 ; p<0.01\right)$. Analysis of simple effects showed that there was a significant effect of individual differences in both pretreatment groups $\left(F_{(1,23)}=14.93, p<0.01\right.$ and $F_{(1,25)}=$ $41.38, p<0.01$ for saline- and cocaine-pretreated animals, respectively), indicating that, regardless of pretreatment, HR rats demonstrated a greater locomotor response to cocaine challenge compared with LRs. However the significant effect of cocaine pretreatment in LR animals $\left(F_{(1,24)}=7.63 ; p=0.011\right)$ and $\mathrm{HR}$ animals $\left(F_{(1,24)}=53.4 ; p<0.01\right)$ showed that sensitization to cocaine develops in both phenotypes.

\section{Characterization of DA dynamics in NAc of HR and LR animals using quantitative microdialysis under transient conditions}

Quantitative microdialysis under transient conditions was used to assess basal and drug-evoked DA dynamics in free moving animals. Figure 2 shows basal and cocaine-evoked DA dynamics 

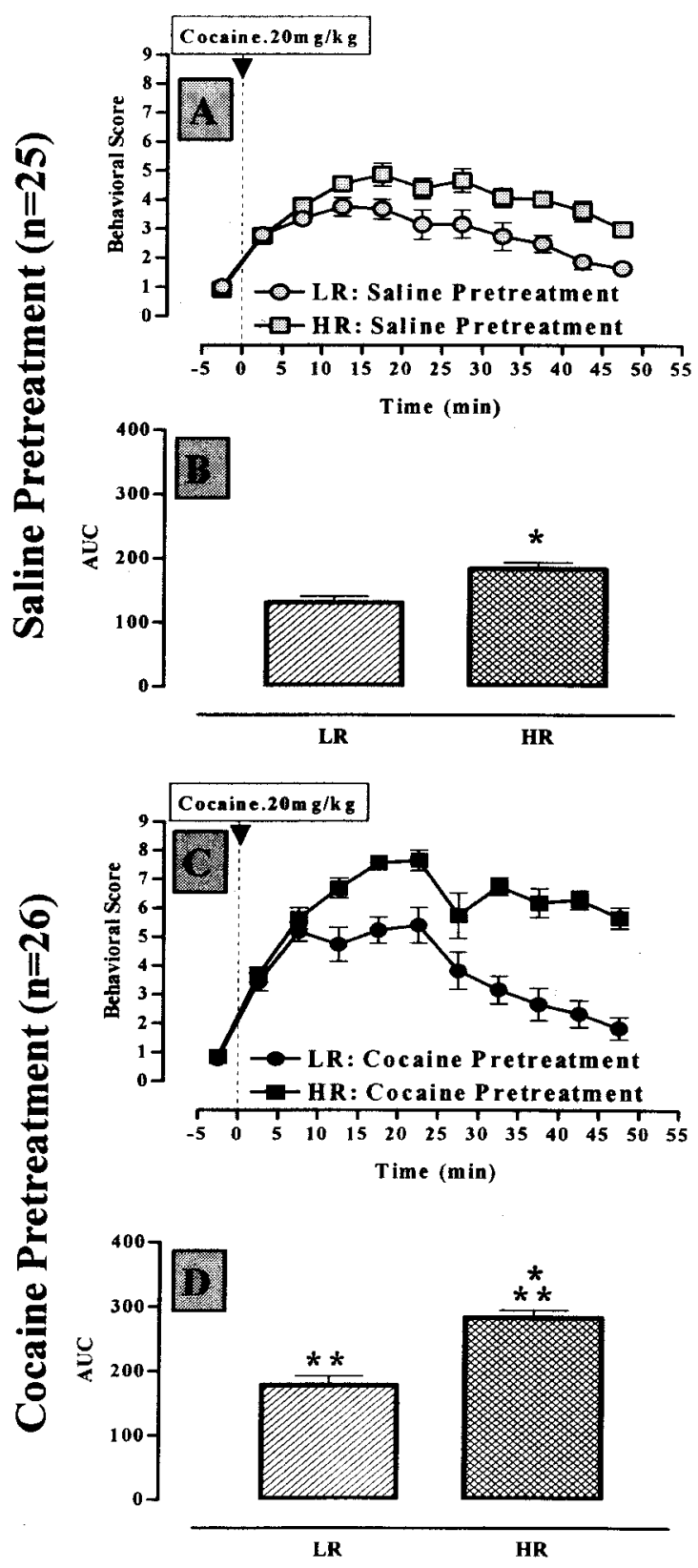

Figure 1. Behavioral response of animals pretreated with saline $(A, B)$ and cocaine $(C, D)$ to a subsequent cocaine $(20 \mathrm{mg} / \mathrm{kg}$, i.p.) challenge on the third day after cessation of the pretreatment regiment. $A$, Time course of the locomotor response to cocaine challenge in $\operatorname{LRs}(\bigcirc)$ and HRs $(\square)$ pretreated with daily injections of saline $(1.0 \mathrm{ml} / \mathrm{kg}$, i.p.) for $5 \mathrm{~d}$. C, Time course of the locomotor response to cocaine challenge in $\mathrm{LRs}(\mathbf{O})$ and HRs $(\boldsymbol{\square})$ pretreated with daily injections of cocaine (20 mg/kg, i.p.) for $5 \mathrm{~d}$. Ordinate: behavioral rating scale modified from Ellinwood and Balster (1974). Data are expressed as means \pm SEM; $n$, number of animals in each experimental group. The abscissa indicates time before and after cocaine injection. Time of -5 corresponds to behavioral score $5 \mathrm{~min}$ before the injection. The dotted line corresponds to the time of cocaine injection. $B, D$, Bar graphs of AUC values for the locomotor response to cocaine challenge in LRs and HRs pretreated with daily injections of either saline $(B)$ or cocaine $(D)$, expressed as the means \pm SEM. ${ }^{*}$ Significant effect of individual differences in both pretreatment groups $(C, D)\left(F_{(1,23)}=14.93, p<0.01\right.$ and $F_{(1,25)}=41.38, p<0.01$ for saline- and cocaine-pretreated animals, respectively). ${ }^{*}$ Significant effect of cocaine pretreatment in $L R$ animals $\left(F_{(1,24)}=7.63 ; p=0.01\right)$ and $\mathrm{HR}$ animals $\left(F_{(1,24)}=53.4 ; p<0.01\right)$.

in saline-pretreated LR and HR (Fig. $2 A, C$ ) animals $3 \mathrm{~d}$ after the cessation of the $5 \mathrm{~d}$ treatment regimens. The mean levels of $\mathrm{DA}_{\text {ext }}$ and the $\mathrm{E}_{\mathrm{d}}$ for both phenotypes are shown in Figure 2, $B$ and $D$, respectively. Two-way ANOVA revealed a significant main effect
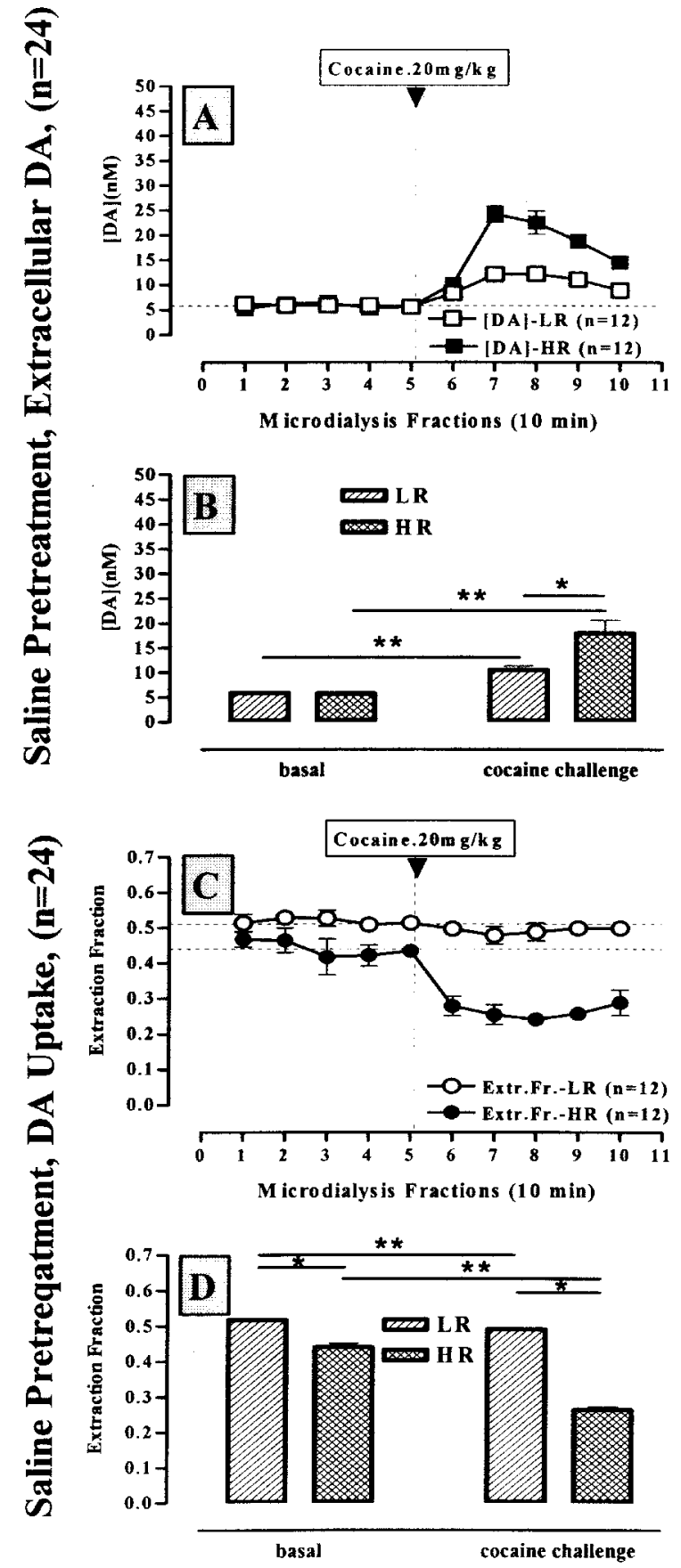

Figure 2. Basal and cocaine-evoked DA dynamics in the NAc of saline-pretreated LR and HR animals assessed by quantitative microdialysis under transient conditions. $A, C$, Time course of extracellular DA ( $A$ ) and extraction fraction ( $C$ ) in LRs ( $\square$ and $\bigcirc$, respectively) and HRs ( $\square$ and -, respectively). The ordinate indicates the extracellular DA (nanomolar) concentration $(A)$ and extraction fraction $(C)$ as a function of time before and after cocaine injection. Each point represents the mean \pm SEM; $n$, number of animals for each experimental group. The abscissa indicates microdialysis fractions (10 $\mathrm{min}$ ) before and after cocaine challenge. The vertical dotted line corresponds to the time of cocaine injection. Horizontal dotted lines indicate the mean values of basal DA concentration $(A)$ and extraction fraction $(C)$ for each experimental group. $B$, $D$, The average values \pm SEM of extracellular DA concentration and extraction fraction, respectively, in LR and HR animals during basal conditions and after cocaine challenge. *Significant effect of individual differences on $\mathrm{DA}_{\text {ext }}$ after cocaine challenge $\left(F_{(1,9)}=7.77 ; p=0.02\right)$ and on extraction fraction during basal conditions $\left(F_{(1,9)}=46.85 ; p<0.01\right)$ and after cocaine challenge $\left(F_{(1,9)}=573.13 ; p<0.01\right)$. ${ }^{*}$ Significant effect of cocaine administration on $\mathrm{DA}_{\text {ext }}(\mathrm{LR}$ : $\left.F_{(1,9)}=32.85, p<0.01 ; \mathrm{HR}: F_{(1,9)}=22.59, p<0.01\right)$ and extraction fraction (LR: $F_{(1,9)}=$ $\left.20,58, p<0.01 ; \mathrm{HR}: F_{(1,9)}=169.64, p<0.01\right)$ in both (LR and HR) experimental groups. 
of individual differences $\left(\mathrm{DA}_{\text {ext }}: F_{(1,19)}=7.49, p=0.015 ; \mathrm{E}_{\mathrm{d}}\right.$ : $\left.F_{(1,19)}=428.19, p \leq 0.01\right)$ as well as a significant effect of drug challenge $\left(\mathrm{DA}_{\text {ext }}: F_{(1,19)}=39.11, p<0.01 ; \mathrm{E}_{\mathrm{d}}: F_{(1,19}=189.19, p<\right.$ $0.01)$. A significant individual differences by drug challenge interaction was also seen for both parameters $\left(\mathrm{DA}_{\mathrm{ext}}: F_{(1,19)}=7.93\right.$, $\left.p=0.012 ; \mathrm{E}_{\mathrm{d}}: F_{(1,19)}=104.93, p<0.01\right)$. Analysis of simple effects revealed a significant effect of cocaine administration on $\mathrm{DA}_{\text {ext }}$ (LRs: $F_{(1,9)}=32.85, p<0.01$; HRs: $F_{(1,9)}=22.59, p<0.01$ ) and $\mathrm{E}_{\mathrm{d}}$ (LRs: $F_{(1,9)}=20,58, p<0.01$; HRs: $F_{(1,9)}=169.64, p<$ $0.01)$, indicating that acute cocaine administration significantly increased $\mathrm{DA}_{\text {ext }}$ and decreased DA uptake in saline-pretreated animals, regardless of phenotype. However, there was a significant effect of individual differences on $\mathrm{E}_{\mathrm{d}}$ during basal conditions $\left(F_{(1,9)}=46.85 ; p<0.01\right)$ and during cocaine challenge $\left(F_{(1,9)}=\right.$ 573.13; $p<0.01)$, indicating that DA uptake differed in LR and $\mathrm{HR}$ animals during basal conditions as well as during the cocaine challenge. On the other hand, there was a significant effect of individual differences on $\mathrm{DA}_{\text {ext }}$ during cocaine challenge $\left(F_{(1,9)}=\right.$ $7.77 ; p=0.024)$ but not during basal conditions $\left(F_{(1,9)}=0.174\right.$; $p=0.68)$, indicating that the concentration of $\mathrm{DA}_{\text {ext }}$ in response to cocaine challenge was significantly higher in HR animals, but basal concentrations of $\mathrm{DA}_{\text {ext }}$ did not differ between groups.

When the same data were expressed as a percentage of basal values (Fig. 3) and subjected to unpaired $t$ tests with Welch's correction, both the mean cocaine-evoked decrease in $\mathrm{E}_{\mathrm{d}}$ and the increase in $\mathrm{DA}_{\text {ext }}$ were significantly greater in $\mathrm{HR}$ compared with LR animals $\left(\mathrm{E}_{\mathrm{d}}: p<0.01, t=16.68, \mathrm{df}=8 ; \mathrm{DA}_{\text {ext }}: p=0.046, t=\right.$ 2.86, $\mathrm{df}=4)$.

Figure 4 shows basal and cocaine-evoked DA dynamics in LR and HR animals $3 \mathrm{~d}$ after cessation of the repeated cocaine treatment regimen. ANOVA revealed a significant main effect of individual differences on $\mathrm{E}_{\mathrm{d}}\left(F_{(1,19)}=67.34 ; p<0.01\right)$ and $\mathrm{DA}_{\mathrm{ext}}$ $\left(F_{(1,19)}=15.11 ; p<0.01\right)$. A significant main effect of acute cocaine administration on the $\mathrm{E}_{\mathrm{d}}\left(F_{(1,19)}=12.82 ; p<0.01\right)$ and $\mathrm{DA}_{\text {ext }}\left(F_{(1,19)}=34.19 ; p<0.01\right)$ as well as a significant individual differences by cocaine interaction $\left(\mathrm{E}_{\mathrm{d}}: F_{(1,19)}=7.43 ; p=0.015\right.$; $\left.\mathrm{DA}_{\text {ext }}: F_{(1,19)}=11.05 ; p<0.01\right)$ were also seen. Cocaine administration significantly decreased the $\mathrm{E}_{\mathrm{d}}$ in $\mathrm{HR}$ rats $\left(F_{(1,9)}=11.96\right.$; $p<0.01)$ but not LR rats $\left(F_{(1,9)}=1.08 ; p=0.3\right)$. In contrast, the acute cocaine challenge significantly increased $\mathrm{DA}_{\mathrm{ext}}$ in both phenotypes $\left(\mathrm{HR}: F_{(1,9)}=22.04, p<0.01\right.$; LR: $F_{(1,9)}=34.62, p<$ $0.01)$. These results indicate that acute cocaine administration significantly decreased DA uptake and increased $\mathrm{DA}_{\text {ext }}$ in cocaine-pretreated HR rats, whereas cocaine-pretreated LR rats demonstrated a significant increase in cocaine-evoked $\mathrm{DA}_{\text {ext }}$ but no effect of cocaine challenge on DA uptake. Analysis of simple effects also showed that there was a significant effect of individual differences on both the basal $\left(F_{(1,9)}=106.92 ; p<0.01\right)$ and cocaine-evoked $\left(F_{(1,9)}=32.14 ; p<0.01\right) \mathrm{E}_{\mathrm{d}}$. Furthermore, although there was a significant effect of individual differences on cocaine-evoked $\mathrm{DA}_{\text {ext }}\left(F_{(1,9)}=13.1 ; p<0.01\right)$, no difference between phenotypes in basal $\mathrm{DA}_{\text {ext }}$ was seen $\left(F_{(1,9)}=\right.$ 3.72; $p=0.09)$. These data indicate that basal DA uptake and cocaine-induced inhibition of DA uptake were significantly different in cocaine pre-exposed LR and HR rats, while a phenotypic difference in $\mathrm{DA}_{\text {ext }}$ was only apparent during cocaine challenge.

Expression of the same data as a percentage of basal values (Fig. 5) revealed that the mean change in $E_{d}$ after cocaine challenge was significantly greater (Student's $t$ test with Welch's correction: $p=0.032 ; t=2.96$; $\mathrm{df}=5)$ in HR animals $(-20.66 \pm$ $5.81 \%)$ than in LR animals $(-2.37 \pm 2.11 \%)$. The mean increase
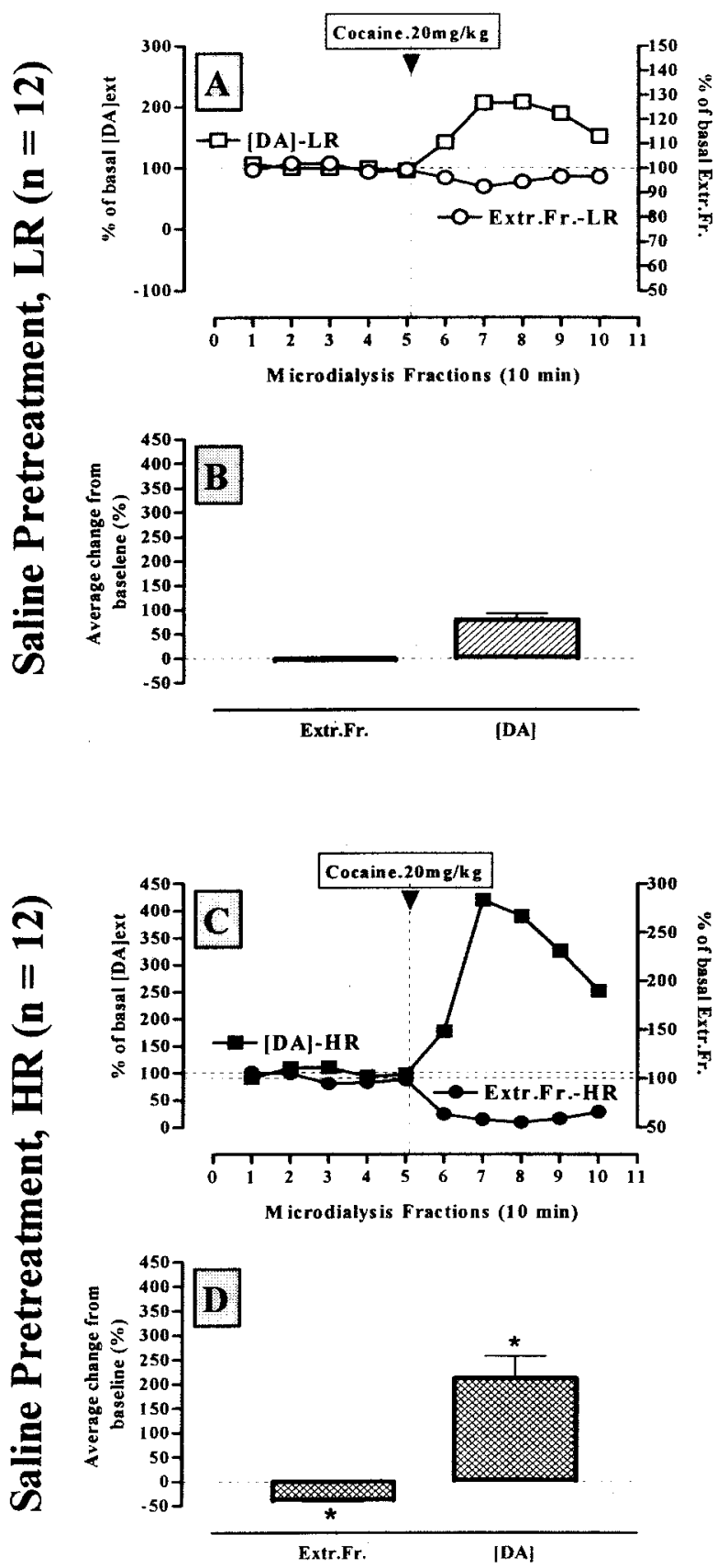

Figure 3. The effect of cocaine challenge on extracellular DA levels and extraction fraction in the NAC of $\operatorname{LR}(A, B)$ and $H R(C, D)$ animals pretreated with saline $(1.0 \mathrm{ml} / \mathrm{kg}$, i.p.). $A$, C, Time course of extracellular DA and extraction fraction in $\operatorname{LRs}(A)$ and $\operatorname{HRs}(C)(A, \square$ and $O ; B$, $\square$ and -, respectively). Left and right ordinate, respectively: extracellular DA concentration and extraction fraction as a percentage of basal values before and after cocaine injection $(20 \mathrm{mg} / \mathrm{kg}$, i.p.). Each point represents the mean $\pm S E M ; n$, number of animals for each experimental group. The abscissa indicates microdialysis fractions ( $10 \mathrm{~min})$ before and after cocaine injection. The vertical dotted line corresponds to the time of cocaine injection. The horizontal dotted lines indicate basal extracellular $D A$ and extraction fraction. $B, D$, The average values of percentage change from baseline for extracellular DA concentration and extraction fraction in $L R$ and $H R$ animals, respectively, after cocaine challenge. *Significant difference in extraction fraction $(p<0.01 ; t=16.68$; $\mathrm{df}=8)$ and extracellular DA $(p=0.04 ; t=2.86 ; \mathrm{df}=4)$ between LR and HR animals.

in cocaine-evoked $\mathrm{DA}_{\text {ext }}$ (HR: $367.3 \pm 76.8 \%$ vs LR: $119.3 \pm$ $20.1 \%$ ) was also significantly greater (Student's $t$ test with Welch's correction: $p=0.035 ; t=3.13$; $\mathrm{df}=4$ ) in HRs compared with LRs. 

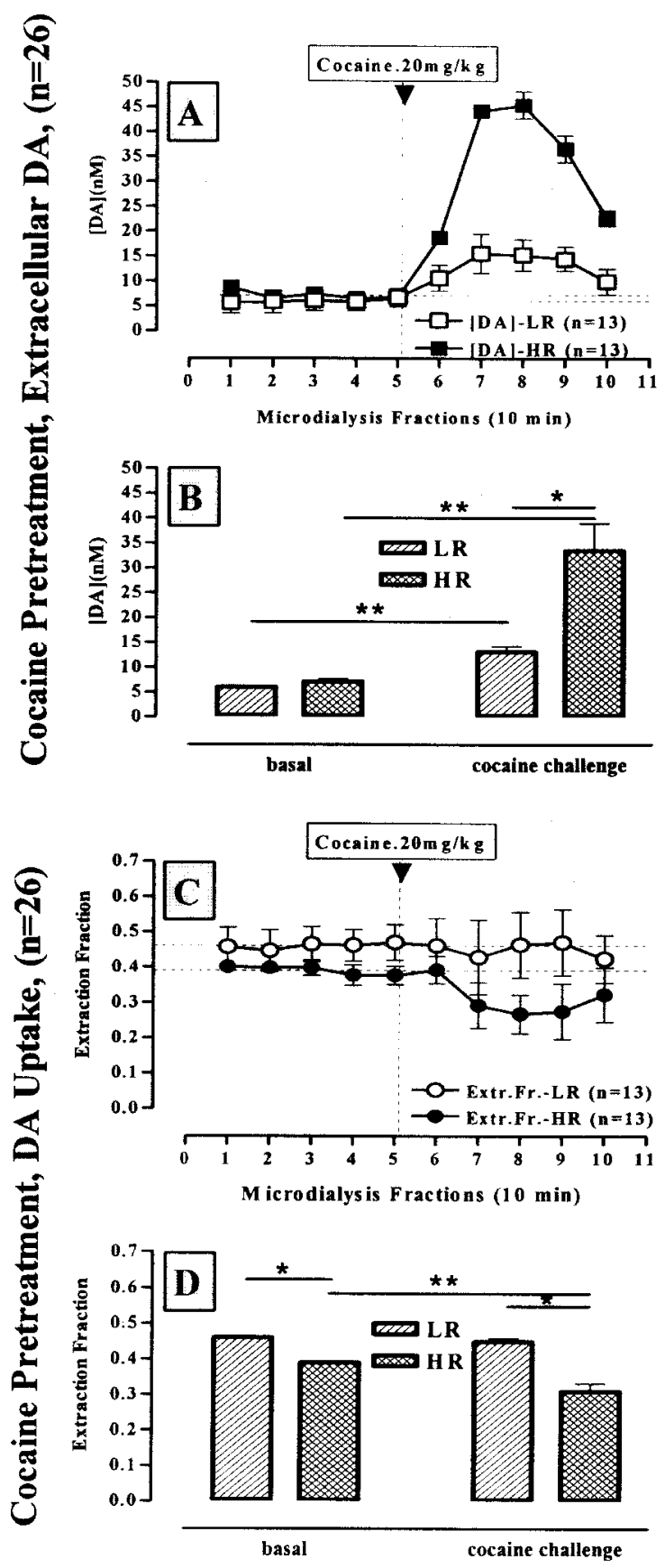

Figure 4. Basal and cocaine-evoked DA dynamics in the NAc of cocaine-pretreated LR and HR animals assessed by quantitative microdialysis under transient conditions. $A, C$, Time course of extracellular DA ( $A$ ) and extraction fraction ( $C$ in LRs ( $\square$ and $\bigcirc$, respectively) and HRs ( $\square$ and -, respectively). The ordinate indicates the extracellular DA (nanomolar) concentration $(A)$ and extraction fraction $(C)$ as a function of time before and after cocaine injection. Each point represents the mean \pm SEM; $n$, number of animals for each experimental group. The abscissa indicates microdialysis fractions ( $10 \mathrm{~min}$ ) before and after cocaine challenge. The vertical dotted line corresponds to the time of cocaine injection. Horizontal dotted lines indicate the mean values of basal DA concentration $(A)$ and extraction fraction ( () for each experimental group. $B$, $D$, The average values $\pm S E M$ of extracellular DA concentration and extraction fraction, respectively, in LR and HR animals during basal conditions and after cocaine challenge. *Significant effect of individual differences on $\mathrm{DA}_{\text {ext }}$ after cocaine challenge $\left(F_{(1,9)}=13.1 ; p<0.01\right)$ and on extraction fraction during basal conditions $\left(F_{(1,9)}=106.92 ; p<0.01\right)$ and after cocaine challenge $\left(F_{(1,9)}=32.14 ; p<0.01\right)$. * Significant effect of cocaine administration on $\mathrm{DA}_{\text {ext }}$ concentration in $\operatorname{LR}\left(F_{(1,9)}=43.62 ; p<0.01\right)$ and $\operatorname{HR}\left(F_{(1,9)}=22.04 ; p<0.01\right)$ animals as well as on extraction fraction in $\operatorname{HRs}\left(F_{(1,9)}=11.96 ; p<0.01\right)$.
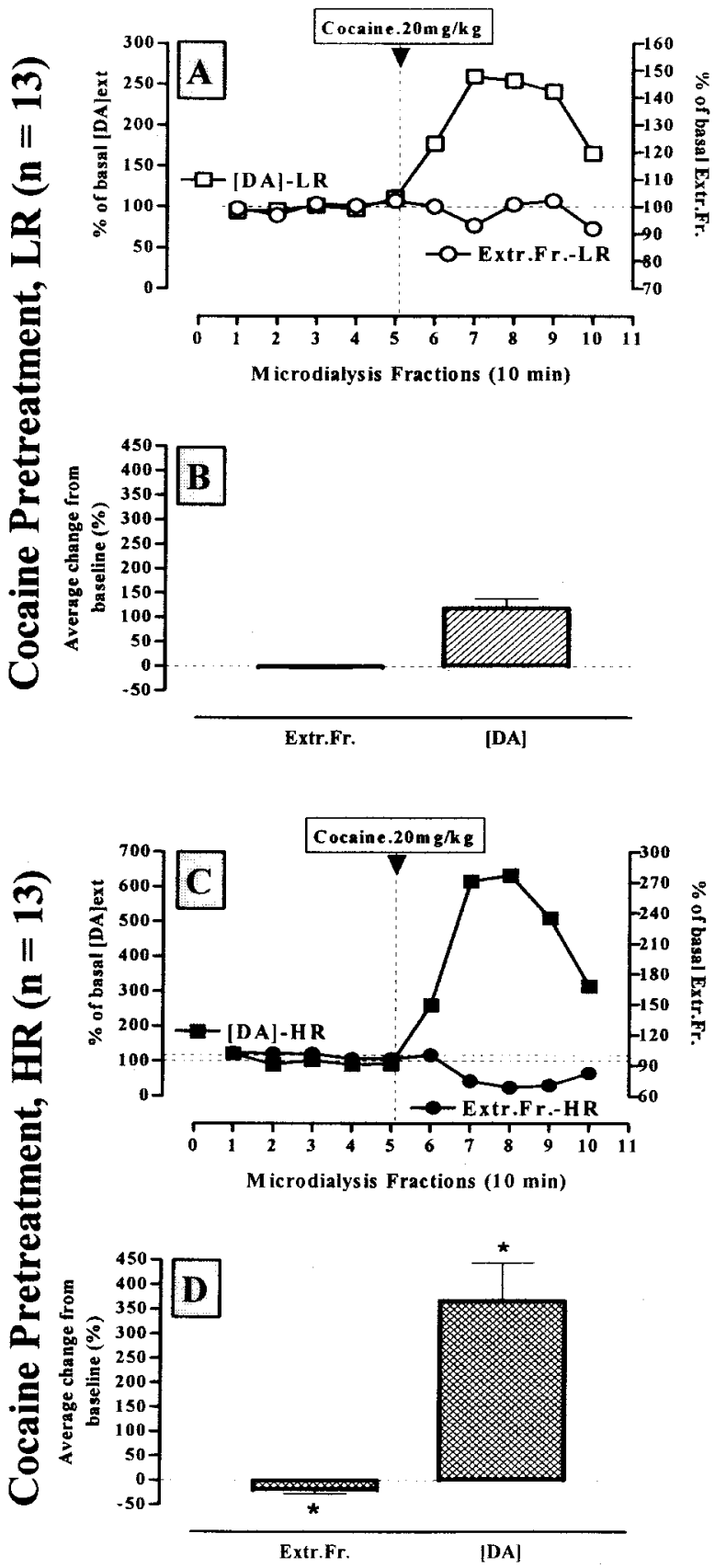

Figure 5. The effect of cocaine challenge on extracellular DA levels and extraction fraction in the NAc of $\operatorname{LR}(A, B)$ and $H R(C, D)$ animals pretreated with cocaine $(20 \mathrm{mg} / \mathrm{kg}$, i.p.). $A$, C, Time course of extracellular $D A$ and extraction fraction in $\operatorname{LRs}(A)$ and $\operatorname{HRs}(C)(A, \square$ and $O ; B$, $\square$ and -, respectively). The left and right ordinate, respectively, indicate extracellular DA concentration and extraction fraction as a percentage of basal values before and after cocaine injection (20 $\mathrm{mg} / \mathrm{kg}$, i.p.). Each point represents the mean \pm SEM; $n$, number of animals for each experimental group. The abscissa indicates microdialysis fractions $(10 \mathrm{~min})$ before and after cocaine injection. The vertical dotted line corresponds to the time of cocaine injection. The horizontal dotted lines indicate basal extracellular DA and extraction fraction. $B, D$, The average values of the percentage change from baseline for extracellular $D A$ concentration and extraction fraction in LR and HR animals, respectively, after cocaine challenge. ${ }^{*}$ Significant difference in extraction fraction ( $p=0.032 ; t=2.96 ; \mathrm{df}=5)$ and extracellular DA concentration $(p=0.035 ; t=$ 3.13; $\mathrm{df}=4$ ) between LR and HR animals.

Characterization of basal DA uptake in minced NAc tissue from HR and LR animals using RDE voltammetry RDE voltammetry was used to characterize the kinetics of DA uptake in the NAc from HR and LR animals (Fig. 6). Analysis of 

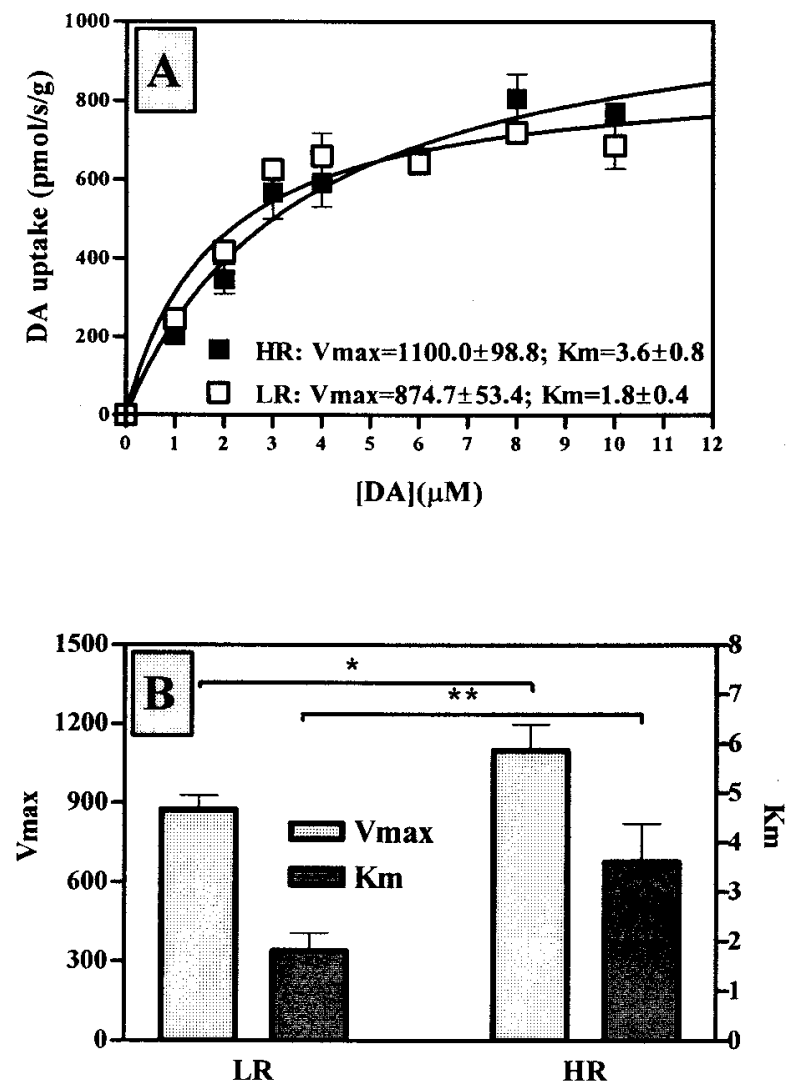

Figure 6. Kinetic analysis of the initial rates of DA uptake in NAc tissue suspension assessed by RDE voltammetry. Values represent the means \pm SEM of the initial velocity of DA uptake in picomoles per second per gram of wet weight tissue. $A$, The kinetic parameters estimated by fitting the data to the Michaelis-Menten equation: $K_{\mathrm{m}}=3.602$ and $1.808 \mu \mathrm{m} ; V_{\max }=1100$ and $874.7 \mathrm{pmol} \cdot \mathrm{sec}^{-1} \cdot \mathrm{gm}^{-1}$ for HRs and LRs, respectively. B, Bar graph of $K_{\mathrm{m}}$ and $V_{\max }$ values expressed as means $\pm S E M$. ${ }^{*}$ Significant difference in $V_{\max }$ between HRs and $\operatorname{LRs}(p=$ $0.040 ; t=2.089 ; \mathrm{df}=74)$. ${ }^{*}$ Significant difference in $K_{\mathrm{m}}(p=0.048 ; t=2.007 ; \mathrm{df}=74)$. Four to five animals were used for each concentration in each group.

the initial velocity of DA uptake showed that the $V_{\max }$ of uptake was significantly higher $(p=0.048 ; t=2.0$; df $=74)$ in HRs $\left(1100 \pm 99.8 \mathrm{pmol} \cdot \mathrm{sec}^{-1} \cdot \mathrm{gm}^{-1}\right)$ compared with LRs $(874.7 \pm$ $\left.53.4 \mathrm{pmol} \cdot \mathrm{sec}^{-1} \cdot \mathrm{gm}^{-1}\right)$. The $K_{\mathrm{m}}$ value for uptake was also significantly greater in $\mathrm{HR}$ animals ( $3.6 \mathrm{vs} 1.8 \mu \mathrm{M} ; p=0.040 ; t=2.1$; $\mathrm{df}=74)$. The $V_{\max } / K_{\mathrm{m}}$ ratio was 0.003 and 0.005 for HRs and LRs, respectively, indicating that the efficiency of basal DA uptake is lower in HRs.

\section{Characterization of DAT function and expression in the NAc} of HR and LRs

Individual differences in basal DA uptake and $\mathrm{DA}_{\text {ext }}$ may result from differences in the activity or expression of the DAT in the NAc of HR and LR animals. Western blot assays of DAT protein content were conducted in NAc synaptosomes to determine whether DAT protein expression differed between the two phenotypes. No difference in DAT immunoreactivity was seen (Fig. 7).

Scatchard analysis of $\left[{ }^{3} \mathrm{H}\right]$ WIN35428 binding to the DAT was conducted in NAc synaptosomes of LR and HR animals. Figure 8 shows that the $B_{\max }$ of $\left[{ }^{3} \mathrm{H}\right]$ WIN35428 binding was significantly higher in HRs compared with LRs (1340 \pm 169 and $821 \pm 64 \mathrm{fmol} / \mathrm{mg}$ protein, respectively; $p<0.05$ by unpaired $t$ test). Analogous, however, to what was observed in uptake studies, the $K_{\mathrm{d}}$ of $\left[{ }^{3} \mathrm{H}\right] \mathrm{WIN} 35428$ binding was also higher in HR compared with LR animals $(5.83 \pm 0.33$ vs $4.19 \pm 0.28 \mathrm{nM}$; Stu-

\section{LR HR}

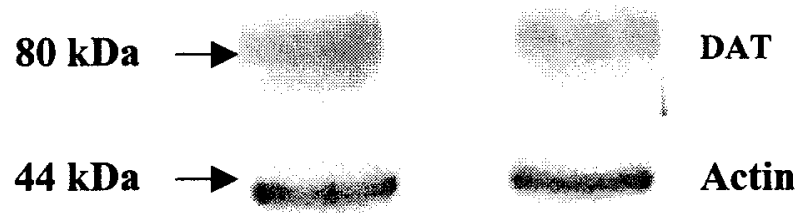

Figure 7. Western blot analysis of DAT from NAc synaptosomes of $L R$ and HR animals. The immunoblot is a representative comparison obtained from one of two independent experiments wherein tissue from three to four animals was examined. Values of DAT protein were normalized by the levels of actin immunoreactivity.

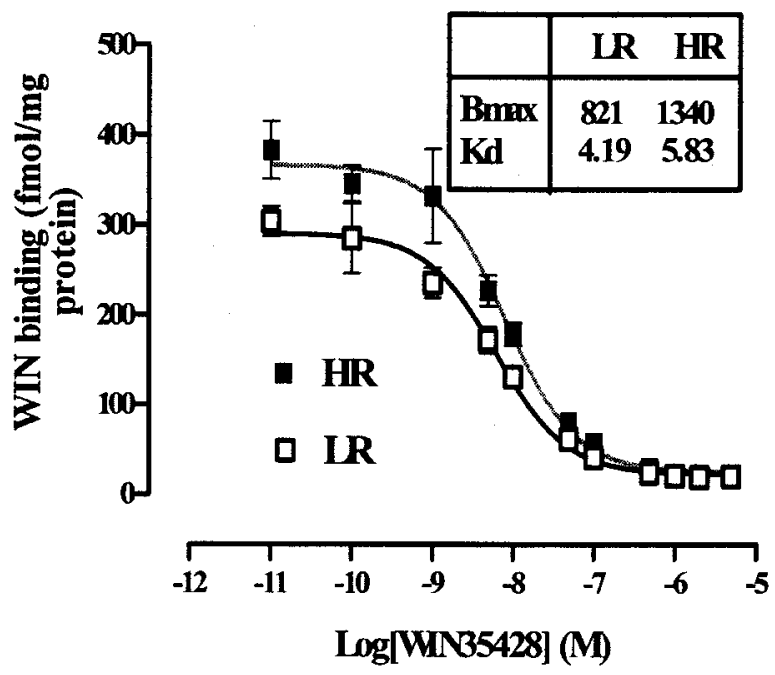

Figure 8. Competitive binding of $\left[{ }^{3} \mathrm{H}\right]$ WIN35428 with unlabeled WIN35428 (WIN) in NAC synaptosomes of HRs $(\square)$ and LRs $(\square)$. Values represent the means \pm SEM of the WIN35428 binding in femtomoles per milligram of protein. The parameters of binding estimated by fitting the data to the Cheng-Prusoffequation were as follows: $K_{d}=5.83 \pm 0.33$ and $4.19 \pm 0.28 \mathrm{~nm}$ (differences between groups were significant; $p<0.05$ by unpaired $t$ test with Welch's correction); $B_{\max }=1340 \pm 169$ and $821 \pm 64 \mathrm{fmol} / \mathrm{mg}$ protein (differences between groups were significant; $p<0.05$ by unpaired $t$ test) for HRs and LRs, respectively. Three to four animals were used for each binding experiment in each group.

dent's $t$ test with Welch's correction; $p<0.05)$, indicating a lower affinity of DAT in HRs.

\section{Discussion}

These studies confirm that the locomotor response to novelty is a reliable predictor of sensitivity to the psychomotor stimulant effects of cocaine (Piazza et al., 1989; Hooks et al., 1991a). Moreover, although all animals that received cocaine repeatedly developed behavioral sensitization, it was more pronounced in HRs than LRs. Microdialysis revealed lower basal DA uptake and a greater cocaine-induced inhibition of uptake in the NAc of drugnaive HRs. Cocaine-evoked increases in $\mathrm{DA}_{\text {ext }}$ were also higher in HRs. Abstinence from repeated cocaine administration decreased basal DA uptake and enhanced cocaine-evoked DA $\mathrm{Axt}_{\text {in }}$ both phenotypes. However, HRs exhibited a greater increase in $\mathrm{DA}_{\text {ext }}$ than LRs. The $K_{\mathrm{m}}$ and $V_{\max }$ of DA uptake in the NAc as well as the $K_{\mathrm{d}}$ and $B_{\max }$ values of $\left[{ }^{3} \mathrm{H}\right] \mathrm{WIN} 35428$ binding were also significantly higher in HRs.

Locomotor response to novelty and sensitivity to cocaine Drug-naive HR rats exhibit greater locomotor activity in response to an acute cocaine challenge than LRs. Three days after 
the cessation of repeated, context-independent cocaine injections, both HRs and LRs exhibited sensitization to the locomotor activating effects of cocaine. However, the magnitude of sensitization was greater in HRs. These findings are consistent with previous studies (Hooks et al., 1991a). They demonstrate that the response to novelty predicts sensitivity to the behavioral activating effect of acute cocaine and the sensitization that develops after repeated cocaine administration.

\section{Lower basal DA uptake and release in HRs}

A previous report (Piazza et al., 1991) showed that the DOPAC/DA ratio, an indirect index of DA release, was higher in NAc homogenates of HRs compared with LRs. In view of the involvement of the mesoaccumbens DA system in novelty as well as the motor and rewarding effects of drugs of abuse, it was hypothesized that enhanced DA neurotransmission underlies the enhanced responsiveness of HR animals. Subsequent microdialysis studies showed that the response to novelty is predictive of individual differences in the responsiveness of the mesoaccumbal DA system to psychostimulants (Hooks et al., 1991b). However, no differences between phenotypes in basal dialysate concentrations of DA were observed. When interpreting both of these findings, however, it is important to note that postmortem analysis of tissue levels of DA and metabolites provides an indirect measure of DA turnover, but actual extracellular levels cannot be determined. In addition, although conventional microdialysis permits assessment of relative changes in neurotransmitter efflux, dialysate neurotransmitter levels are affected by alterations in extracellular levels as well as in uptake. Furthermore, differences in transporter-mediated neurotransmitter reuptake can affect the $\mathrm{E}_{\mathrm{d}}$ of the microdialysis probe (Justice, 1993; Smith and Justice, 1994), leading to an underestimation or overestimation of actual extracellular levels.

The no-net-flux method of quantitative microdialysis (Lonnroth et al., 1987; Parsons and Justice, 1994) provides an estimate of extracellular neurotransmitter concentration that is independent of changes in uptake. Using this technique, Hooks et al. (1992) reported that HRs had higher basal DA ${ }_{\text {ext }}$ concentration than LRs. Surprisingly, although subsequent studies (Shippenberg and Thompson, 1997; Shippenberg et al., 1999) have shown that differential effects of a particular manipulation on extracellular compared with dialysate levels are caused by differences in $\mathrm{E}_{\mathrm{d}}$, this parameter was unchanged.

The present studies demonstrate that drug-naive HRs had a lowered basal and cocaine-evoked $\mathrm{E}_{\mathrm{d}}$ compared with LRs. Furthermore, basal $\mathrm{DA}_{\text {ext }}$ concentration did not differ between groups. Methodological differences may underlie the contrasting results obtained. In contrast to the previous study, in which animals were perfused with several concentrations of DA to quantify $\mathrm{DA}_{\text {ext }}$, each animal was perfused with only one concentration, preventing potential confounds resulting from insufficient equilibrium time. Second, a randomized and counterbalanced presentation of the various DA concentrations was not used in the previous study. Finally, decreased DA uptake in HRs was also observed using RDE voltammetry, a technique that permits direct assessment of the DA clearance rate in vitro, indicating that the no-net-flux technique used in the present study enabled a valid assessment of basal DA dynamics. Consistent with the present data, DAT knock-down mice, which exhibit decreased DA uptake relative to wild types, showed normal activity in the home cage but were significantly more active than wild types after exposure to a novel environment (Zhuang et al., 2001). Interestingly, unlike the DAT knock-down mice, the lower basal DA uptake in HRs compared with LRs was not accompanied by an elevation of $\mathrm{DA}_{\mathrm{ext}}$, suggesting that basal DA release is decreased in HRs. Kinetic analysis of DA clearance in RDE studies revealed that both the $K_{\mathrm{m}}$ and $V_{\max }$ were higher in HRs. The higher $K_{\mathrm{m}}$ is consistent with the decreased basal DA uptake observed in microdialysis experiments.

DAT expression did not differ in the NAc of LR and HR rats. However, these results do not enable differentiation of the cytosolic versus membrane DAT expression. $\left[{ }^{3} \mathrm{H}\right]$ WIN35428 binding revealed that the affinity of binding is decreased in HRs relative to LRs, but that DAT number is increased. The lower binding affinity in HRs is consistent with the lower affinity of uptake in this phenotype and likely underlies the decreased basal uptake of HRs, whereas an increased number of functionally active DATs and increased maximal capacity of DA clearance in HRs would compensate, at least partially, for the decreased affinity. Under nonchallenged conditions, when synaptic DA concentrations are low, changes in affinity rather than transporter number may be of greater importance in determining uptake rate. However, under challenged conditions, when DA concentrations are high, an increased number of DATs could provide a mechanism for enhanced DA clearance. The question remains as to why the cocaine inhibition of uptake is greater in HRs. Interestingly, a recent study showed that the inhibition of DA uptake by cocaine may result solely from a decrease in the affinity of DA uptake (Wu et al., 2001). Thus, cocaine-evoked increases in $K_{\mathrm{m}}$, coupled with the increased $K_{\mathrm{m}}$ for basal uptake in HRs, may underlie the greater response to cocaine in these animals.

\section{Greater cocaine-evoked extracellular DA in HRs}

Acute cocaine increases $\mathrm{DA}_{\text {ext }}$ via binding to the DAT and blocking DA uptake into the nerve terminals (Kuhar et al., 1990). Interestingly, it can also abolish dendritic DA release and the resulting autoinhibition of DA neurons (Falkenburger et al., 2001). Although these findings remain controversial because of the ability of cocaine to reduce cell firing, they suggest another possible mechanism that may contribute to the increase in extracellular DA levels in the NAc.

In the present study, acute cocaine challenge increased $\mathrm{DA}_{\mathrm{ext}}$ in all groups. The magnitude of this effect was greater in HRs regardless of whether the data were expressed as absolute values or as the percentage increase from baseline. This finding differs from that of Hooks et al. (1992), who found no difference between phenotypes in percentage increase of $\mathrm{DA}_{\text {ext }}$ after cocaine. One explanation for this discrepancy is that $\mathrm{E}_{\mathrm{d}}$ determined during basal conditions was used to calculate $\mathrm{DA}_{\text {ext }}$ after cocaine challenge. As demonstrated by Smith and Justice (1994), uptake is the primary neuronal process affecting $\mathrm{E}_{\mathrm{d}}$. Because cocaine inhibits uptake and decreases the $\mathrm{E}_{\mathrm{d}}$, the use of basal $\mathrm{E}_{\mathrm{d}}$ for calculation of cocaine-evoked $\mathrm{DA}_{\text {ext }}$ would lead to an underestimation of actual values. Furthermore, if the magnitude of uptake inhibition by cocaine differed in the two phenotypes, as observed in this study, a confounding of $\mathrm{DA}_{\text {ext }}$ would occur.

\section{DA dynamics in NAc after chronic cocaine}

Basal DA uptake was decreased $3 \mathrm{~d}$ after the cessation of cocaine treatment. However, the difference in basal uptake observed in naive HRs and LRs was maintained. Furthermore, although cocaine-evoked $\mathrm{DA}_{\text {ext }}$ was increased at this abstinence time point, the increase was greater in cocaine-treated HRs. In contrast, the decrease in $\mathrm{E}_{\mathrm{d}}$ was smaller than in naive HRs ( -21 vs $\left.-40 \%\right)$, suggesting that the ability of cocaine to inhibit DA cell firing, and thus decrease DA release, may be lessened in HRs pre-exposed to 
cocaine. Thus, drug-naive HRs and those with a previous cocaine history exhibit diminished basal DA release but enhanced DA release during the cocaine challenge relative to LRs. Moreover, there was no significant effect of cocaine challenge on $E_{d}$ in cocaine-pretreated LRs ( $-3 \%$ from the baseline). Therefore, we speculate that the increased $\mathrm{DA}_{\text {ext }}$ in these animals is primarily attributable to changes in DA release.

Abstinence from an identical cocaine treatment resulted in reduced basal DA release and enhanced K-evoked DA release as well as DA release observed during a cocaine challenge (Chefer and Shippenberg, 2002). In that study, changes in DA release after cocaine pretreatment could be attributed in part to a subsensitivity of $\mathrm{D}_{2}$ autoreceptors in the NAc. Interestingly, $\mathrm{D}_{2}$ receptor density is lower in the NAc of HRs compared with LRs (Hooks et al., 1994). Given the documented role of $\mathrm{D}_{2}$ receptors in regulation of DA release and DAT function, the altered $\mathrm{D}_{2}$ receptor function may be one mechanism contributing to the differences in DA dynamics observed in these phenotypes.

\section{DA neurotransmission and individual vulnerability to drugs of abuse}

Although it is likely that several mechanisms determine vulnerability to the behavioral effects of psychostimulants, our studies highlight the potential role of presynaptic DA neurotransmission in mediating individual differences in responsiveness to cocaine. These studies show that basal DA uptake and release are reduced in individuals that exhibit greater activity in an open field and an enhanced behavioral response to cocaine. The binding affinity of the DAT is also lower in these animals, an effect that is in part compensated for by increased DAT number. The increase in $\mathrm{DA}_{\text {ext }}$ produced by a cocaine challenge is greater in these animals regardless of whether they were drug naive or pre-exposed to cocaine, suggesting that DA release is increased. It was shown recently that lower basal DA release and uptake in the NAc compared with the caudate putamen is associated with greater cocaine-evoked $\mathrm{DA}_{\text {ext }}$ in this region (Wu et al., 2001). This finding and that of the present study indicate an inverse relationship between basal DA dynamics and responsiveness to novelty and cocaine.

\section{References}

Chefer VI, Shippenberg TS (2002) Changes in basal and cocaine-evoked extracellular dopamine uptake and release in the rat nucleus accumbens during early abstinence from cocaine: quantitative determination under transient conditions. Neuroscience 112:907-919.

Earles C, Schenk JO (1998) Rotating disk electrode voltammetric measurements of dopamine transporter activity: an analytical evaluation. Anal Biochem 264:191-198.

Ellinwood EHJ, Balster RL (1974) Rating the behavioral effects of amphetamine. Eur J Pharmacol 28:35-41.

Falkenburger BH, Barstow KL, Mintz IM (2001) Dendrodendritic inhibition through reversal of dopamine transport. Science 293:2465-2470.

Hooks MS, Kalivas PW (1995) The role of mesoaccumbens-pallidal circuitry in novelty-induced behavioral activation. Neuroscience 64:587-597.

Hooks MS, Jones GH, Smith AD, Neill DB, Justice JBJ (1991a) Individual differences in locomotor activity and sensitization. Pharmacol Biochem Behav 38:467-470.

Hooks MS, Jones GH, Smith AD, Neill DB, Justice JBJ (1991b) Response to novelty predicts the locomotor and nucleus accumbens dopamine response to cocaine. Synapse 9:121-128.

Hooks MS, Colvin AC, Juncos JL, Justice JBJ (1992) Individual differences in basal and cocaine-stimulated extracellular dopamine in the nucleus accumbens using quantitative microdialysis. Brain Res 587:306-312.

Hooks MS, Juncos JL, Justice JBJ, Meiergerd SM, Povlock SL, Schenk JO, Kalivas PW (1994) Individual locomotor response to novelty predicts selective alterations in D1 and D2 receptors and mRNAs. J Neurosci 14:6144-6152.

Justice JBJ (1993) Quantitative microdialysis of neurotransmitters. J Neurosci Methods 48:263-276.

Kokoshka JM, Vaughan RA, Hanson GR, Fleckenstein AE (1998) Nature of methamphetamine-induced rapid and reversible changes in dopamine transporters. Eur J Pharmacol 361:269-275.

Kuhar MJ, Sanchez-Roa PM, Wong DF, Dannals RF, Grigoriadis DE, Lew R, Milberger M (1990) Dopamine transporter: biochemistry, pharmacology, and imaging. Eur Neurol 30 [Suppl 1]:15-20.

Lonnroth P, Jansson PA, Smith U (1987) A microdialysis method allowing characterization of intercellular water space in humans. Am J Physiol 253:E228-E231.

Meiergerd SM, Schenk JO (1995) Measurement of the time-resolved kinetics of biogenic amine release and transporter activity by rotating disk electrode voltammetry. Neuromethods 27:305-336.

Olson RJ, Justice JBJ (1993) Quantitative microdialysis under transient conditions. Anal Chem 65:1017-1022.

Parsons LH, Justice JBJ (1994) Quantitative approaches to in vivo brain microdialysis. Crit Rev Neurobiol 8:189-220.

Parsons LH, Smith AD, Justice JBJ (1991a) Basal extracellular dopamine is decreased in the rat nucleus accumbens during abstinence from chronic cocaine. Synapse 9:60-65.

Parsons LH, Smith AD, Justice JBJ (1991b) The in vivo microdialysis recovery of dopamine is altered independently of basal level by 6-hydroxydopamine lesions to the nucleus accumbens. J Neurosci Methods 40:139-147.

Paxinos, G, Watson, C (1986) The rat brain in stereotaxic coordinates. San Diego: Academic.

Piazza PV, Le Moal ML (1996) Pathophysiological basis of vulnerability to drug abuse: role of an interaction between stress, glucocorticoids, and dopaminergic neurons. Annu Rev Pharmacol Toxicol 36:359-378.

Piazza PV, Deminiere JM, Le Moal M, Simon H (1989) Factors that predict individual vulnerability to amphetamine self-administration. Science 245:1511-1513.

Piazza PV, Rouge-Pont F, Deminiere JM, Kharoubi M, Le Moal M, Simon H (1991) Dopaminergic activity is reduced in the prefrontal cortex and increased in the nucleus accumbens of rats predisposed to develop amphetamine self-administration. Brain Res 567:169-174.

Povlock SL, Schenk JO (1997) A multisubstrate kinetic mechanism of dopamine transport in the nucleus accumbens and its inhibition by cocaine. J Neurochem 69:1093-1105.

Rouge-Pont F, Piazza PV, Kharouby M, Le Moal M, Simon H (1993) Higher and longer stress-induced increase in dopamine concentrations in the nucleus accumbens of animals predisposed to amphetamine selfadministration. A microdialysis study. Brain Res 602:169-174.

Sabeti J, Gerhardt GA, Zahniser NR (2002) Acute cocaine differentially alters accumbens and striatal dopamine clearance in low and high cocaine locomotor responders: behavioral and electrochemical recordings in freely moving rats. J Pharmacol Exp Ther 302:1201-1211.

Shippenberg TS, Thompson AC (1997) Overview of microdialysis. In: Protocols in neuroscience. Neurochemistry/Neuropharmacology: Unit 7 (Skolnick P, ed), pp 7.1.1-7.1.22. New York: Wiley.

Shippenberg TS, He M, Chefer V (1999) The use of microdialysis in the mouse: conventional versus quantitative techniques. Psychopharmacology (Berl) 147:33-34.

Smith AD, Justice JB (1994) The effect of inhibition of synthesis, release, metabolism and uptake on the microdialysis extraction fraction of dopamine. J Neurosci Methods 54:75-82.

Thompson AC, Zapata A, Justice JB, Vaughan RA, Sharpe LG, Shippenberg TS (2000) $\kappa$-Opioid receptor activation modifies dopamine uptake in the nucleus accumbens and opposes the effects of cocaine. J Neurosci 20:9333-9340.

Wu Q, Reith ME, Kuhar MJ, Carroll FI, Garris PA (2001) Preferential increases in nucleus accumbens dopamine after systemic cocaine administration are caused by unique characteristics of dopamine neurotransmission. J Neurosci 21:6338-6347.

Zapata A, Shippenberg TS (2002) D(3) receptor ligands modulate extracellular dopamine clearance in the nucleus accumbens. J Neurochem 81:1035-1042.

Zhuang X, Oosting RS, Jones SR, Gainetdinov RR, Miller GW, Caron MG, Hen R (2001) Hyperactivity and impaired response habituation in hyperdopaminergic mice. Proc Natl Acad Sci USA 98:1982-1987. 